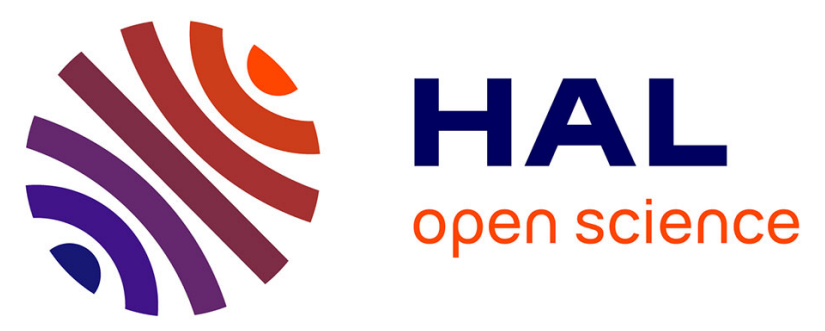

\title{
On the friction effect on the characteristics of hydroformed tube in a square section die: analytical, numerical and experimental approaches
}

Abir Abdelkefi, Nathalie Boudeau, Pierrick Malecot, Gérard Michel, Noamen Guermazi

\section{To cite this version:}

Abir Abdelkefi, Nathalie Boudeau, Pierrick Malecot, Gérard Michel, Noamen Guermazi. On the friction effect on the characteristics of hydroformed tube in a square section die: analytical, numerical and experimental approaches. Key Engineering Materials, 2015, 639, pp.83-90. 10.4028/www.scientific.net/KEM.639.83 . hal-02131276

\author{
HAL Id: hal-02131276 \\ https://hal.science/hal-02131276
}

Submitted on 7 May 2021

HAL is a multi-disciplinary open access archive for the deposit and dissemination of scientific research documents, whether they are published or not. The documents may come from teaching and research institutions in France or abroad, or from public or private research centers.
L'archive ouverte pluridisciplinaire HAL, est destinée au dépôt et à la diffusion de documents scientifiques de niveau recherche, publiés ou non, émanant des établissements d'enseignement et de recherche français ou étrangers, des laboratoires publics ou privés. 


\title{
On the friction effect on the characteristics of hydroformed tube in a square section die: analytical, numerical and experimental approaches
}

\author{
Abir Abdelkefi ${ }^{1,2, a}$, Nathalie Boudeau ${ }^{1,3, b}$, Pierrick Malécot ${ }^{1,3, c}$, \\ Gérard Michel ${ }^{1,3, \mathrm{~d}}$ and Noamen Guermazi ${ }^{2, e}$ \\ ${ }^{1}$ FEMTO-ST Institute, Department of Applied Mechanics, 24 rue Epitaphe, 25000 Besançon, \\ France \\ ${ }^{2}$ Université de Sfax, Département Génie des Matériaux, Sfax, Tunisie \\ ${ }^{3}$ ENSMM, 26 rue Epitaphe, 25000 Besançon, France \\ aabir.abdelkefi@femto-st.fr, ${ }^{b}$ nboudeau@ens2m.fr, ${ }^{c}$ pierrick.malecot@ens2m.fr, \\ 'gerard.michel@ens2m.fr, ${ }^{\mathrm{e}}$ noamen.guermazi@gmail.com
}

Keywords: Hydroforming, friction, modelling

\begin{abstract}
A focus on the effect of friction condition on tube hydroforming during corner filling in a square section die is proposed. Three approaches have been developed: an analytical model from the literature has been programmed, finite element simulations have been conducted and experiments have been carried out. Effect of friction coefficient on the thickness distribution in the square section of the hydroformed tube is studied. Critical thinning is found to take place in the transition zone between the straight wall and the corner radius and this minimal thickness seems to be the more appropriate parameter for the evaluation of the friction coefficient.
\end{abstract}

\section{Introduction}

Nowadays, industries spend a lot of effort to meet new environmental standards and become more competitive. As a result of these economic considerations, companies must reduce their costs and control their capacity. Originally reserved for manufacturing high-tech components in the field of aerospace, hydroforming is increasingly used for aeronautical and automotive applications to meet these new economic constraints. Indeed, this process provides some advantages, for example: weight reduction, part consolidation, lower tooling cost, improved structural strength and stiffness, avoided secondary operations and reduced scrap [1].

Despite all these advantages this technique presents some drawbacks such as expensive equipment, slow cycle time, and lack of extensive knowledge base for process and tool design [1]. So, numerous researches using analytical or finite element models and experiments have been carried out on tube hydroforming [2-4]. The success of tube hydroforming process depends on the material properties of the tube to be formed, the tube and dies geometries, and friction conditions. The friction coefficient directly affects the flow of material in the die and then, the thickness repartition over the final component. In fact, when the friction coefficient increases, localized thinning takes place [5].

Processes design requires more and more the use of finite element simulations where the friction can be modelled with the classical Coulomb's friction coefficient. The classical test for this friction coefficient is the pin-on-plate test which is not representative of the actual surfaces in contact during metal forming processes. That explains the numerous methods proposed in the literature for measuring the friction coefficient $[6,7]$.

Several authors have developed the corner filling test where a tube is expanded in a square cross section die; thus, the friction contacts take place in the part of the formed tube. This specific die geometry presents an interest because lots of hydroformed parts have this kind of geometry, in automotive application for instance. Kridli et al., [2] have proposed a finite element model of the corner filling test to study the impact of corner radius and hardening exponent on the thickness variation at the corner. Hwang and Chen [3] have developed a mathematical model that introduces the sliding friction between the tube and the die. This model has been used to predict the necessary 
pressure for forming a tube in a square cross section die and to predict the thickness distribution. A numerical model was developed showing a good agreement with the mathematical model. Chen [4] has studied the effect of friction on the thickness distribution by finite element simulation. Sun et al., [8] have proposed a non finite element model to analyze the stress distribution in the corner of a square section hydroformed tube. Usually, the thickness is maximal at the central point of the flat part of the shaped tube, while the thinning occurs in the transition zone between the flat part and the radius of the formed tube. Orban and $\mathrm{Hu}$ [9] have proposed an analytical model for the expansion of circular tube into a square section die, to investigate the variation in stress and strain along the tube wall when the internal pressure increases. Friction and material properties affect the thickness distribution in the hydroformed tube. This last study helps in the search for limits of the process capabilities. $\mathrm{Xu}$ et al.[10] have conducted theoretical works where they studied the thickness distribution along the cross section of the middle cross-section of square sectional parts. A numerical study showed again that the thinning is located in the transition zone, while the thickest element is located in the middle of the straight wall. The effects of the friction coefficient, the strain-hardening exponent ' $n$ ' and the anisotropy coefficient ' $r$ ' on the distribution of thickness in square section of hydroformed parts are largely explored [2,11]. In fact, an increase in the friction coefficient reduces the uniformity of the thickness in the straight wall, while a high value of ' $n$ ' and ' $r$ ' promotes the uniformity of thickness

The test of tube expansion test in a square die has been modelled by Orban and $\mathrm{Hu}$ [9]. It takes the form of a semi-analytical problem that could present an interesting tool for the characterization of the Coulomb's friction coefficient, under conditions close to real tube hydroforming process. In the present paper, the authors propose to study the friction conditions with the Orban-Hu model and FE simulations. Experiments of tube hydroforming in a square die are also proposed.

The paper is organized as following:

- Sections 2, 3 and 4 present the Orban-Hu model, the FE simulations and the experiments respectively;

- Section 5 proposes comparisons between the results obtained with the semi-analytical model and the FE simulations;

- Section 6 is devoted to the first comparisons between experiments and models.

Finally, concluding remarks and perspectives are reported in the last section.

\section{Theoretical model}

The Orban-Hu model [9] deals with the corner filling in tube hydroforming in a square die. It considers two distinctive parts named the corner and the wall as represented in Fig. 1. Mechanical equilibrium of the corner is only related to the internal pressure and plane strain assumption is considered. For the wall, tangential forces due to friction effect is also taken into account; moreover, stick and slip conditions are considered. For example, the stick/slip frontier is represented by $x_{s t}$ in Fig. 1. With this mathematical model, it is then possible to evaluate the evolution of the corner radius, wall length, corner thickness and thickness along the wall within the internal pressure. Its theoretical development has been possible by considering the material following a Swift hardening law. The Orban-Hu model has been programmed with Matlab@ and validated with results presented in their paper [9].

The solution procedure is summarized by the following set of equations:

$$
\left[\begin{array}{cccc}
2-\frac{\pi}{2} & 2 & \frac{\pi r}{2} & 0 \\
-P & 0 & 0 & 1 \\
0 & 0 & 1 & -\beta_{c} \\
0 & 1 & 0 & -C_{2}
\end{array}\right]\left\{\begin{array}{c}
\Delta r \\
\Delta l_{w} \\
\Delta \varepsilon_{c} \\
\Delta F_{c}
\end{array}\right\}=\left\{\begin{array}{c}
0 \\
r \Delta P \\
0 \\
C_{1} \Delta P
\end{array}\right\}
$$

where $\Delta P$ is the increment in internal pressure, $r$ the current corner radius, $\beta_{c}$ a parameter linked to the current corner thickness and the current slope to the hardening curve, $C_{1}$ and $C_{2}$ two "constants" which depend on the friction coefficient, the current internal pressure, the current slope to the hardening curve and the increase in length of the contact surface in the wall area. The 
resolution of this set of equations permits to calculate the increase of the corner radius $\Delta r$, contact length in the wall $\Delta l_{w}$, the strain in the corner $\Delta \varepsilon_{c}$ and the friction force $\Delta F_{c}$.

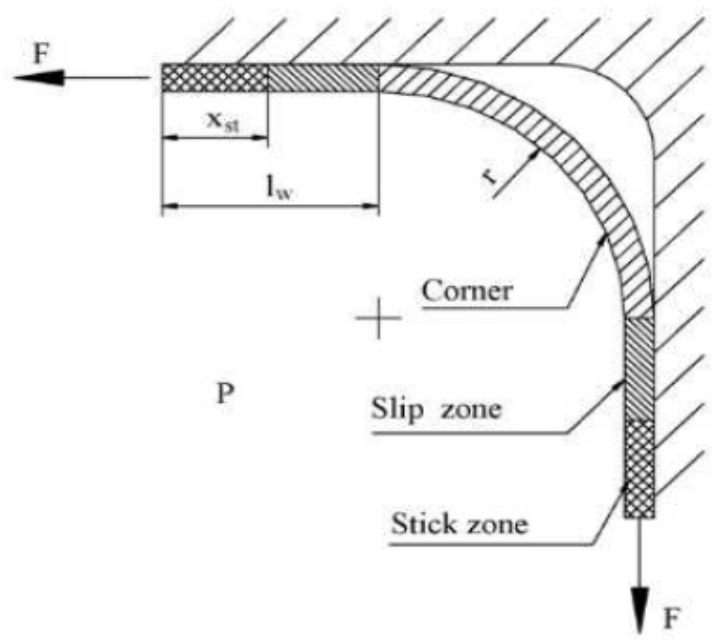

Figure 1: Corner and wall areas considered for the Orban-Hu 2007 model with stick/slip consideration (from Ref. [9])

\section{Finite element model}

Fig. 2 shows the finite element half-model for tube hydroforming in a square die. The simulations are run with LS-DYNA/ExplicitC software [12]. The geometry is meshed with 51448 nodes and 51164 Belytschko-Tsay shell elements. The element size is based on the smaller detail in the model, meaning the die corner radius $r=5 \mathrm{~mm}$. The die is supposed to be a rigid material. The tube material, a copper, is considered elastic-plastic and isotropic; in the plastic range, it follows the Swift law: $\bar{\sigma}(M P a)=263.63(0.0043+\bar{\varepsilon})^{0.287}$. The Swift parameters have been identified from experimental hardening curve obtained with the tube bulging test [13]. The tube is clamped at its two ends. Finally, an internal pressure is applied on the inner surface of the tube; it varies from 15 to $28 \mathrm{MPa}$, based on experimental measurements, in a virtual period of $0.001 \mathrm{~s}$. Different friction coefficients $(\mu=0.05$. and $\mu=0.1)$ between tube and die are considered to study the thickness distribution in the final component. Post-processing the numerical results will consist in analyzing the evolution of thickness reduction, thickness spatial repartition and die radius evolution in relation with the different friction conditions.

The main dimensions for the copper tube and the results are given in Table 1.

Table 1: Dimensions for tubes and main results

\begin{tabular}{|c|c|c|c|c|c|}
\hline $\begin{array}{c}\text { Half model } \\
\text { length } \\
(\mathbf{m m})\end{array}$ & $\begin{array}{c}\text { External tube } \\
\text { radius (mm) }\end{array}$ & $\begin{array}{c}\text { Tube } \\
\text { thickness } \\
\mathbf{( m m})\end{array}$ & $\begin{array}{c}\text { Friction } \\
\text { value }\end{array}$ & $\begin{array}{c}\text { Thickness } \\
\text { reduction } \\
\mathbf{( \% )}\end{array}$ & $\begin{array}{c}\text { Final corner } \\
\text { radius (mm) }\end{array}$ \\
\hline 125 & 17.5 & 1 & 0.05 & 20.5 & 5.32 \\
\hline 125 & 17.5 & 1 & 0.1 & 21.5 & 5.23 \\
\hline
\end{tabular}



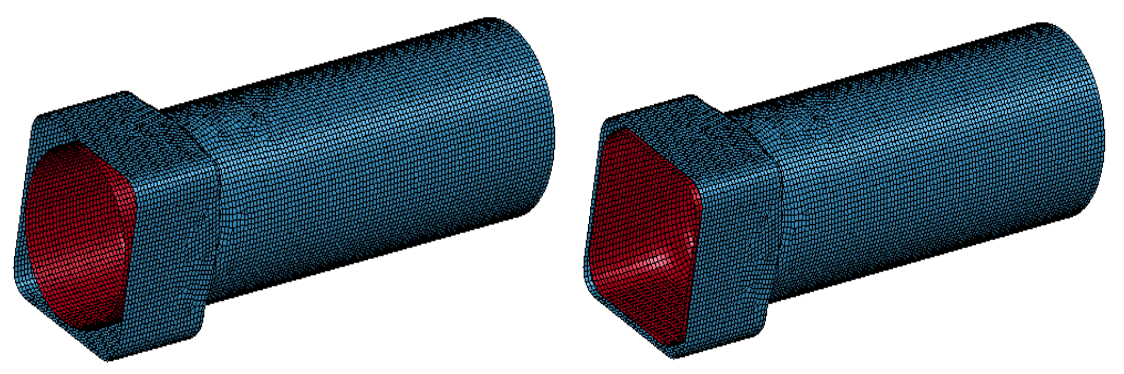

Figure 2: FE model (a) and typical FE results (b)

\section{Tube hydroforming in a square section die}

A modular tool has been designed to run tube bulging tests in an open die or tube hydroforming in closed shape dies. This tool is installed in a press. The experimental devices are illustrated in Fig. 3. A multiplier pressure cylinder creates the high pressure to bulge the tube and two vertical cylinders clamp the tube at its two extremities by cone-cone contacts. The test proceeds as following: (1) conical plungers come in contact with the ends of the tube; (2) the hydraulic fluid is pumped into the specimen through the conical plungers resulting in a slow increasing pressure inside the tube. (3) the tube deforms and takes, little by little, the shape of the die. During the hydroforming process, the internal pressure inside the tube and the tube deformation are measured. In the present test, the maximal internal pressure was $28 \mathrm{MPa}$ that allows a tube expansion without any risk of crack (Fig.4). This maximal pressure was estimated through numerical simulations and optimization procedure. The tests are conducted without specific lubricant, but the tools are oiled to avoid their degradation.

(a)

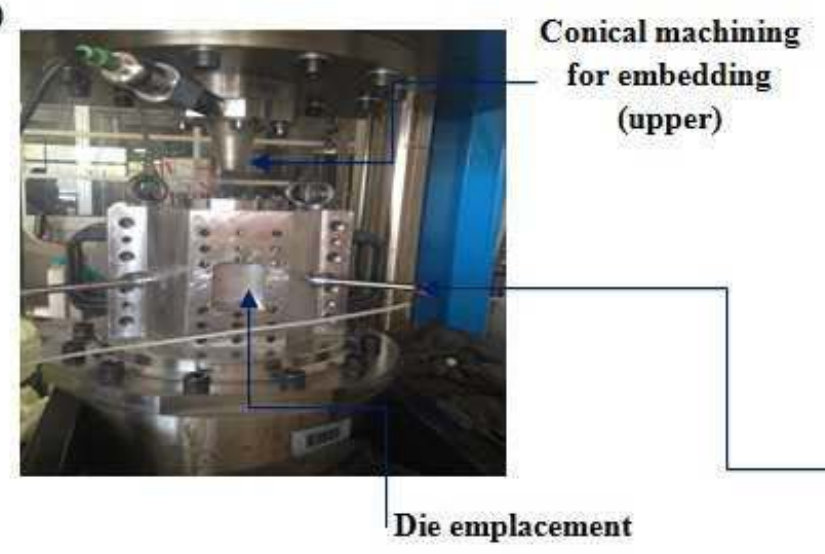

(b)

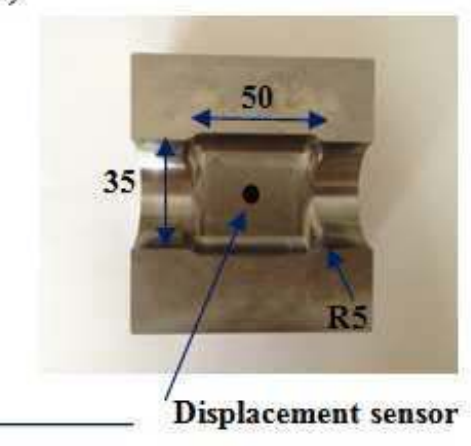

Figure 3: The modular tool installed on the press at FEMTO-ST lab (a) and the main dimensions of the square section die (b)
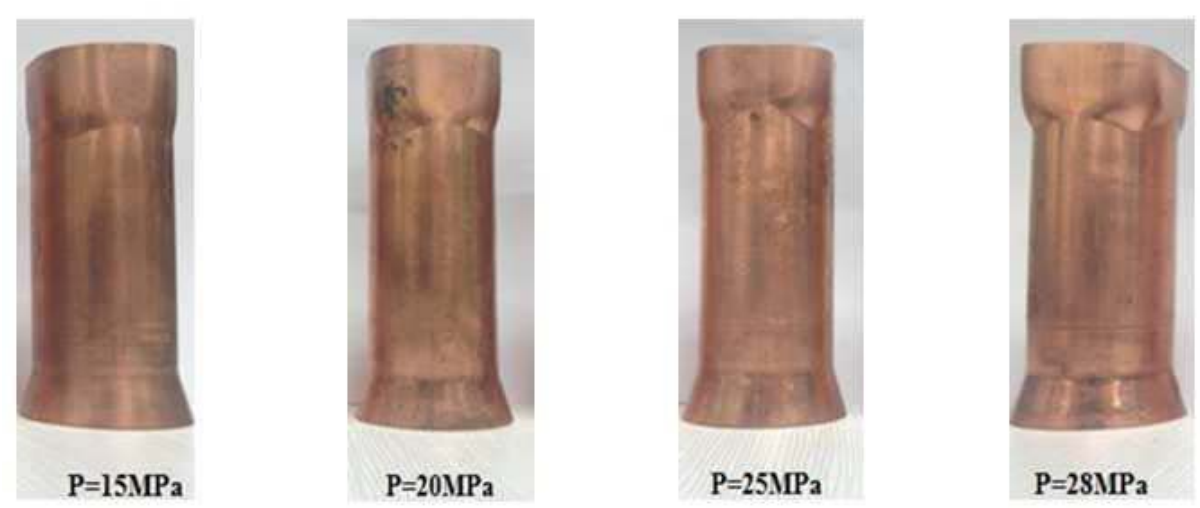

Figure 4: Tube after expansion in a square die with various internal pressures: experimental results. 


\section{Validation of Orban-Hu 2007 model with numerical simulations}

In this section, results obtained from the Orban-Hu model and from finite element simulation are compared. Two friction coefficient values $(\mu=0.05 . \mu=0.1)$ are studied. Fig. 5.a represents the variation of the corner thickness vs. the corner radius when the pressure increases from 15 to 28 $\mathrm{MPa}$. When the friction coefficient increases from 0.05 to 0.1 the corner thickness decreases for both the numerical simulations and the analytical model. Despite the $6 \%$ of difference between numerical and analytical results, the two approaches show similar evolutions. It is found that the influence of the friction coefficient has very weak effect for the both approaches; the values of 0.05 and 0.1 for the friction coefficient are certainly not enough to find a correlation between the friction coefficient and the corner characteristics. In the contrary, the evolution of the corner thickness with the corner radius differs for the two approaches. The Orban-Hu model leads to a larger thickness reduction than for the FE simulations. These differences can be related to different facts: 1) The Orban-Hu model is based on plane strain hypothesis as the FE model is a 3D model, meshed with shell elements. 2) As there is no remeshing during the FE simulations, the resulting corner radius and corner thickness can be averaged. 3) Finally, the two simulations are governed with a pressure increment that is not similar in the two simulations; for FE simulations, the mesh size is governing the time step based on the smallest element, as it is imposed for running the Orban-Hu model. Fig. 5.b illustrates the effect of friction coefficient on the wall thickness at the end of the process, corresponding to an internal pressure of $28 \mathrm{MPa}$, and again, analytical and numerical results are compared. Globally, the results obtained with the semi-analytical approach and the FE simulations are comparable for the smallest friction coefficient considered in this study $(\mu=0.05)$. For $\mu=0.1$, the FE model leads to a weaker thickness in the wall than the Orban-Hu model. It is also found that the thickness is more important in the central area of the wall for the highest friction coefficient; in the contrary, the thickness is much weaker when the area close to the corner zone is considered. Such an evolution is logical; when sticky contact appears in the wall, the thickness stops decreasing to the detriment of the thickness in the area near the corner that continues to decrease. The differences are linked to the difference of the two models. Orban-Hu model considers that all the sections of the tube deform the same way that is not the case in the FE simulations and in the experiments. And the FE model manages the contact conditions according to the mesh.
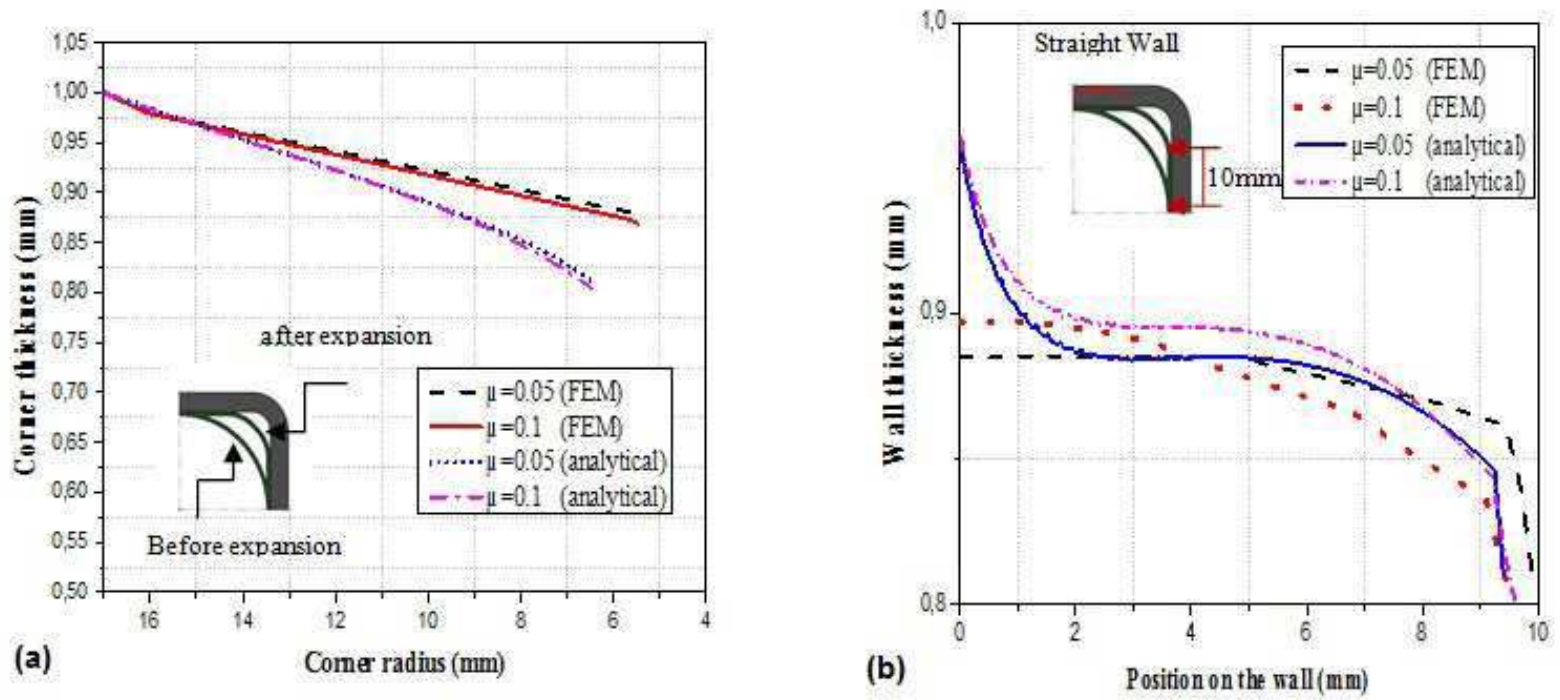

Figure 5: (a) The variation of the corner thickness vs .corner radius for different friction coefficients. (b) The variation of the wall thickness vs. position on the wall with different friction coefficients for $\mathrm{P}=28 \mathrm{MPa}$.

The evolution of the contact length with the internal pressure is plotted in Fig. 6.a. As it can be observed in Fig. 6.a the contact length increases with the internal pressure. At the early step, the pressure is very low, and then the contact length is very small; after, a sticking zone occurs at 
middle stage. For the FE results, the evolution of the contact length stops because the mesh size does not permit to fill completely the corner.

To study the effect of friction on the corner filling, various friction coefficients have been used in the FE simulations: $\mu=0.05$ to 0.25 . When the friction coefficient increases from 0.05 to 0.25 , the corner radius decreases as it can be observed in Fig. 6.b, but the differences are very weak. The corner radius is certainly not the best parameter for an evaluation of the friction coefficient.

(a)

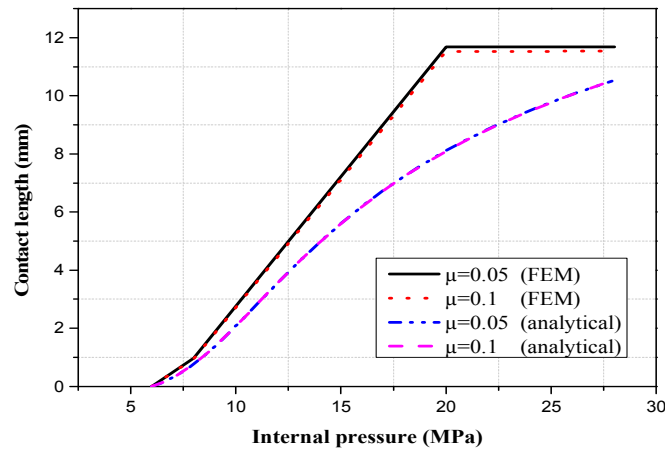

(b)

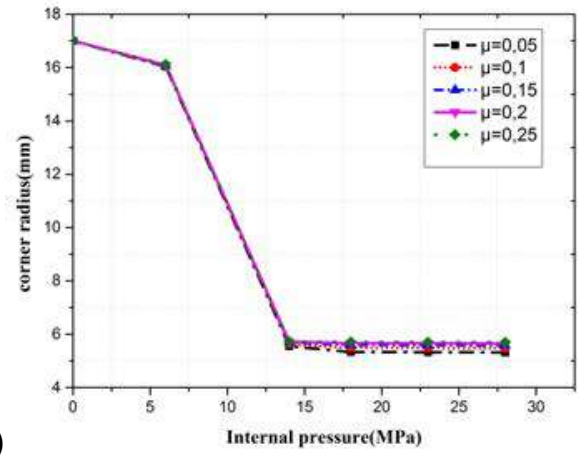

Figure 6: (a) The evolution of the contact length vs. internal pressure with different friction coefficients. (b) The effect of friction coefficient on the corner radius.

\section{Comparison between numerical, theoretical and experimental results}

In this section, comparisons are done on the minimal thickness evolution and Fig. 7 illustrates the measures done on the samples.

(a)

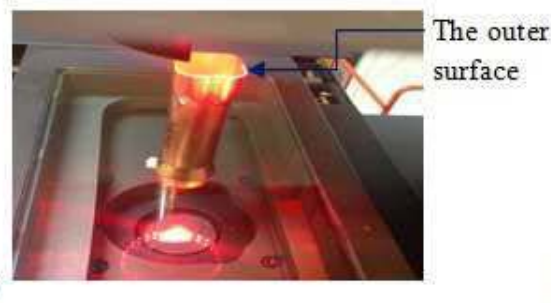

(b)

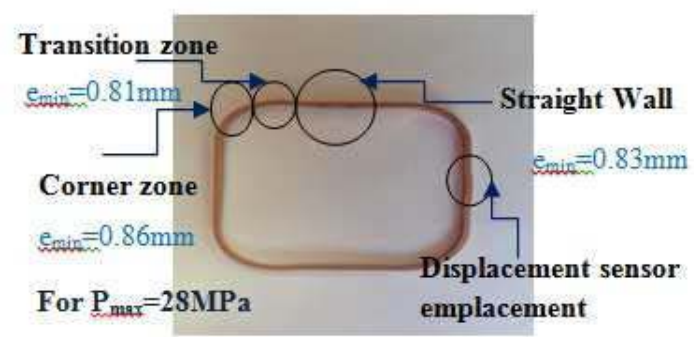

Figure 7: Thickness measures done on the shaped tube samples (a) and resulting zones in the tube.

The minimum thickness obtained in the hydroformed part is plotted against the corresponding internal pressure in Fig. 8 where numerical results obtained with FE simulations and the Orban-Hu model, for two different values for the friction coefficient, are compared with the measures done on the real hydroformed part. The values for the friction coefficient have been chosen from experimental results obtained on pin-on-plane tests realized at the University of Sfax with samples corresponding to the two materials in contact during tube hydroforming. The numerical results show the same tendency: the minimum thickness is weaker when the friction coefficient is larger. But these results are distinct, certainly due to the different hypothesis; in the FE simulations, the thickness is minimal as the shell elements are subject to biaxial stretching, that is not the case in the Orban-Hu model. The differences with the experimental measures are very large. They can be linked to: 1) the friction coefficient is not characteristic of the real friction conditions during tube hydroforming 2) the 3D shell model is not sufficiently precise for thickness evaluation. 


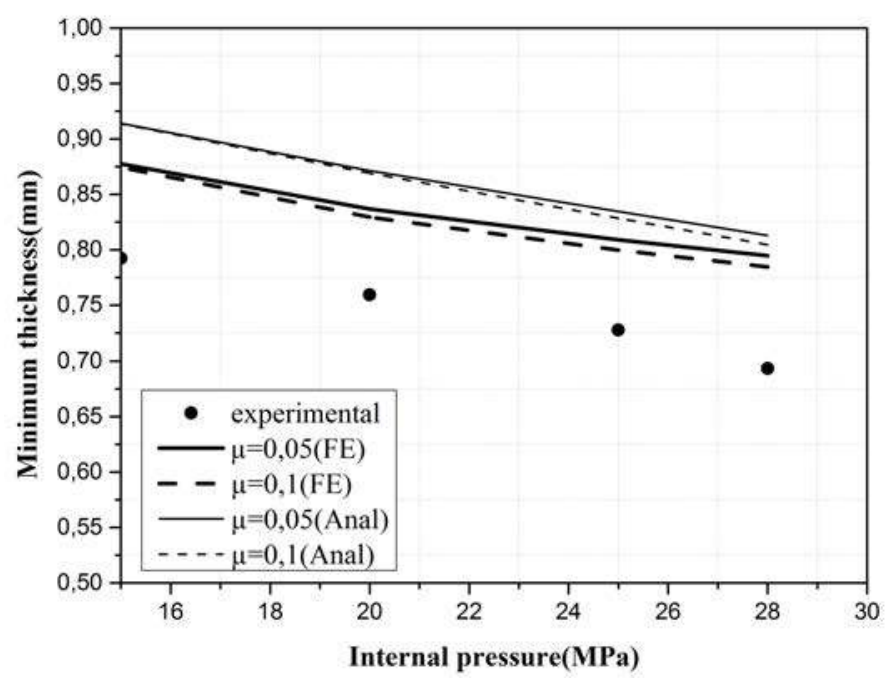

Figure 8: Comparison of thickness variation vs. pressure for the experimental result: numerical simulation and analytical result.

\section{Conclusion}

The paper has proposed the study of friction effect and thinning during tube hydroforming in a square die with the analytical model developed by Orban and $\mathrm{Hu}$, numerical simulations with LSDYNA/Explicit software and experiments. Comparisons between results obtained with these three approaches have been done.

The tendencies are well described by the two numerical approaches but it is difficult to find similar results. Amongst the different parameters that can be post-processed, the minimal thickness seems to be the best for the evaluation of the friction coefficient.

The difficulty to find similar results is due on the different assumptions done for the two numerical approaches: the Orban-Hu model considers that a slice of the shaped tube is representative of the tube hydroforming in a square die and does not take account what happen along the tube length.

The finite element simulations are certainly more representative of the real process but, a model based on shell elements can lead to an overestimation of the thickness. A 3D model with solid finite elements would be more appropriate for the evaluation of the minimal thickness.

Even if the present results are not entirely satisfying, this work presents interesting perspectives:

- Comparison between shell model and solid model for the FE simulations, and the activation of remeshing, would give indications on the possibility to evaluate the friction coefficient with the proposed approach.

- FE simulations for different length of the square die would help for designing the experimental test, reduce the border effects and establish the domain of validity of the OrbanHu model for friction evaluation.

- The experimental tests could be carried out with different interface conditions to validate the evolution of several parameters with the friction conditions.

\section{References}

[1] Ahmetoglu.M., Altan.T., Tube hydroforming: state-of-the-art and future trends, Journal of materials Processing Technology, 98 (2000) 25-33.

[2] Kridli G.T., Bao.L., Mallick P-K., Tian.Y., Investigation of thickness variation and corner filling in tube hydroforming, Journal of Materials Processing Technology, 33 (2003) 287-296.

[3] Hwang Y.M., Chen W-C., Analysis of tube hydroforming in a square cross-sectional die, International Journal of Plasticity, 21 (2005) 1815-1833. 
[4] Chen K.K., The effects of friction on bursting of tubes in corner filling. SAE Technical Paper Series, 2003-01-0688.

[5] Yi H.K., Yim H.S., Lee G.Y., Lee S.M., Chung G.S., Moon Y.H., Experimental investigation of friction coefficient in tube hydroforming, Journal of Transactions of Nonferrous Metals Society of China, 21 (2011) 194-198.

[6] Vollertsen F., Plancak M., On possibilities for the determination of the coefficient of friction in hydroforming of tubes, Journal of materials Processing Technology, 125-126 (2002) 412-420.

[7] Plancak M., Vollertssen F., Woitschig J., Analysis finite element simulation and experimental investigation of friction in tube hydroforming, Journal of Materials Processing Technology, 170 (2005) 220-228.

[8] Sun.Z. C., Debray K., Li Y. M., Guo Y. Q., Design-modeling optimization of addendum surface in deep drawing. In Proceeding of the First International Conference of New Forming Technology, (2004) 271-276.

[9] Orban H., Hu S.J., Analytical modeling of wall thinning during corner filling in structural tube hydroforming, Journal of Materials Processing Technology, 194 (2007) 7-14.

[10] Xu X., Li S., Zhang W., Lin Z., Analysis of thickness distribution of square-sectional hydroformed parts, Journal of Materials Processing Technology, 209 (2009) 158-164.

[11]Zribi T., Khalfallah A., Belhadjsalah H., Analyse de l'effet des paramètres matériaux sur 'hydroformage des tubes. Congrès Tunisien de Mécanique, Hammamet, Tunisie 2008.

[12] J.O. Hallquist, LS-DYNA3D User Manual v970, LSTC, Livermore, 1989.

[13]N. Boudeau, P. Malécot, A simplified analytical model for post-processing experimental results from tube bulging test: Theory, experimentations, simulations, International Journal of Mechanical Sciences, 65 (2012) 1-11. 